\title{
Business-as-usual will lead to super and ultra-extreme heatwaves in the Middle East and North Africa
}

\author{
George Zittis (iD ${ }^{1 凶}$, Panos Hadjinicolaou ${ }^{1}$, Mansour Almazroui ${ }^{2}$, Edoardo Bucchignani ${ }^{3,4}$, Fatima Driouech ${ }^{5}$, Khalid El Rhaz ${ }^{6}$, \\ Levent Kurnaz $\mathbb{D}^{7,8}$, Grigory Nikulin ${ }^{9}$, Athanasios Ntoumos ${ }^{1}$, Tugba Ozturk ${ }^{10}$, Yiannis Proestos ${ }^{1}$, Georgiy Stenchikov ${ }^{11}$, \\ Rashyd Zaaboul ${ }^{12}$ and Jos Lelieveld (iD) ${ }^{1,13}$
}

Global climate projections suggest a significant intensification of summer heat extremes in the Middle East and North Africa (MENA). To assess regional impacts, and underpin mitigation and adaptation measures, robust information is required from climate downscaling studies, which has been lacking for the region. Here, we project future hot spells by using the Heat Wave Magnitude Index and a comprehensive ensemble of regional climate projections for MENA. Our results, for a business-as-usual pathway, indicate that in the second half of this century unprecedented super- and ultra-extreme heatwave conditions will emerge. These events involve excessively high temperatures (up to $56^{\circ} \mathrm{C}$ and higher) and will be of extended duration (several weeks), being potentially life-threatening for humans. By the end of the century, about half of the MENA population (approximately 600 million) could be exposed to annually recurring super- and ultra-extreme heatwaves. It is expected that the vast majority of the exposed population (>90\%) will live in urban centers, who would need to cope with these societally disruptive weather conditions.

npj Climate and Atmospheric Science (2021)4:20; https://doi.org/10.1038/s41612-021-00178-7

\section{INTRODUCTION}

The manifestation of human-induced global warming in the Mediterranean region, including the Middle East and North Africa (MENA), is expected to become particularly pronounced in the 21 st century ${ }^{1}$. Climate projections, even under low greenhouse gas emission pathways, indicate significant and relatively rapid warming, in addition to less robust but substantial changes of precipitation $^{2,3}$. The regional warming is found to follow a differential seasonal response with a much stronger temperature increase projected for the boreal summer compared to the rest of the year ${ }^{4}$. As a result of the rising warm-season temperatures, heatwaves can be expected to increase in frequency, magnitude, and duration ${ }^{5-8}$. The observed trends in heat extremes corroborate the model simulations and the transition to much warmer conditions, which started in the $1980 \mathrm{~s}^{9-17}$.

The potential intensification of heatwaves in the already harsh, hot and arid MENA environment is expected to have direct negative impacts on human health ${ }^{18,19}$, agriculture ${ }^{20}$, the water and energy nexus ${ }^{21,22}$, and many other socioeconomic sectors. For example, heat stress can cause substantial loss of labor productivity $^{23}$ and may also be linked to conflict and migration ${ }^{24}$. Livestock in the MENA region will also be affected since the majority of the camel, cattle, and goat populations are located in areas of high vulnerability ${ }^{25}$. Regarding the impacts on human health, in particular, exposure to elevated temperatures is linked to heat cramps, heat syncope, heat exhaustion, and heat-stroke, especially among the elderly and those with pre-existing conditions, such as cardiovascular and respiratory diseases ${ }^{26}$. Under high greenhouse gas emission and concentration pathways, in parts of the Middle East, e.g., near the Arabian Gulf, the combined effect of high temperature and humidity is projected to reach or even exceed the thresholds for human adaptability ${ }^{27,28}$. Mass gathering events in the MENA, such as the Muslim Pilgrimage or Hajj, may be particularly affected by extreme heat conditions. For example, Kang et al. ${ }^{29}$ cautioned for future increases in the frequency and intensity of heat stress in Mecca during the Hajj, with health consequences under both businessas-usual and mitigation scenarios. The region is also characterized by pronounced inequalities, and the poor are expected to suffer most from climate change impacts on water and land resources, health, and energy systems ${ }^{30}$.

The human population of the MENA region, including the northern, eastern, and southern Mediterranean countries, is currently close to one billion inhabitants, and this is projected to increase rapidly in the coming decades. Furthermore, the level of urbanization is high and increasing ${ }^{31}$ with a further concentration of the population in large metropolitan centers being expected. Therefore, additional thermal stress, typically a factor not considered in global and regional climate projections, is expected to be introduced through the urban heat island (UHI) effect ${ }^{32}$.

To date, the scientific literature on heatwave projections in the MENA region is mostly based on global simulations at relatively coarse resolution, or on regional modeling of the edges of European and Mediterranean model domains that underrate the entirety of MENA weather regimes as well as the pronounced topography, which govern the regional climate. A recent MENAfocused climate downscaling initiative that fully considers the particularities of the region aims to provide the much-needed high-quality regionalized information and is dedicated to the

\footnotetext{
${ }^{1}$ Climate and Atmosphere Research Center (CARE-C), The Cyprus Institute, Nicosia, Cyprus. ${ }^{2}$ Center of Excellence for Climate Change Research/Department of Meteorology, King Abdulaziz University, Jeddah, Saudi Arabia. ${ }^{3}$ Euro Mediterranean Center on Climate Change (CMCC), Capua, Italy. ${ }^{4}$ Italian Aerospace Research Center (CIRA), Capua, Italy. ${ }^{5}$ University Mohammed VI Polytechnic, Ben Guerir, Morocco. ${ }^{6}$ Direction Générale de la Météorologie (DGM), Casablanca, Morocco. ${ }^{7}$ Department of Physics, Faculty of Science and Arts, Bogazici University, Istanbul, Turkey. ${ }^{8} \mathrm{Center}$ for Climate Change and Policy Studies, Bogazici University, Istanbul, Turkey. ${ }^{9}$ Rossby Centre, Swedish Meteorological and Hydrological Institute, Norrköping, Sweden. ${ }^{10}$ Department of Physics, Faculty of Sciences and Arts, Isik University, Istanbul, Turkey. ${ }^{11}$ Division of Physical Sciences and Engineering, King Abdullah University of Science and Technology, Thuwal, Saudi Arabia. ${ }^{12}$ International Center for Biosaline Agriculture, Dubai, UAE. ${ }^{13}$ Department of Atmospheric Chemistry, Max Planck Institute for Chemistry, Mainz, Germany. ${ }^{凶}$ email: g.zittis@cyi.ac.cy
} 
modeling of this extraordinary climate change hot-spot. This is pursued through the Middle East-North Africa hub of the Coordinated Regional Downscaling Experiment (CORDEX), i.e., MENA-CORDEX (http://mena-cordex.cyi.ac.cy/). Although there is an increasing number of MENA-CORDEX studies focusing on individual model optimization and validation ${ }^{33-39}$, as well as several future projections for the region ${ }^{19,40-42}$, here we present a multi-model ensemble approach. The main objectives of our study are (i) to evaluate the ability of this multi-model ensemble to simulate the MENA climate with a focus on temperature extremes in the warm season, (ii) to project heatwave characteristics for the MENA region under a scenario of high greenhouse gas concentrations, and (iii) to estimate the potential exposure of the population to extreme thermal conditions. We particularly address the aspects of heatwaves that are expected to have consequences for human health and society. These include heatwave magnitude, amplitude, duration, and frequency.

\section{RESULTS}

\section{Comparison with observations}

The 30-year (1981-2010) mean and maximum warm-season (MaySeptember) daily maximum temperature (tasmax) was derived from each of the MENA-CORDEX ensemble members (Supplementary Table S1) and compared with reanalysis and gridded observations (Fig. 1). On average, for the MENA land regions (defined in Methods and Supplementary Fig. S1), most of the models reproduce the magnitude and temporal evolution of warm-season average and maximum tasmax reasonably well (Fig. 1a). For the warm-season absolute maxima and most of the years, the gridded observations and reanalysis datasets fall within the MENA-CORDEX model spread. However, the regional simulations tend to slightly underestimate the maximum temperature,

(a) Warm season Tasmax (1981-2010) averaged for MENA (land only)

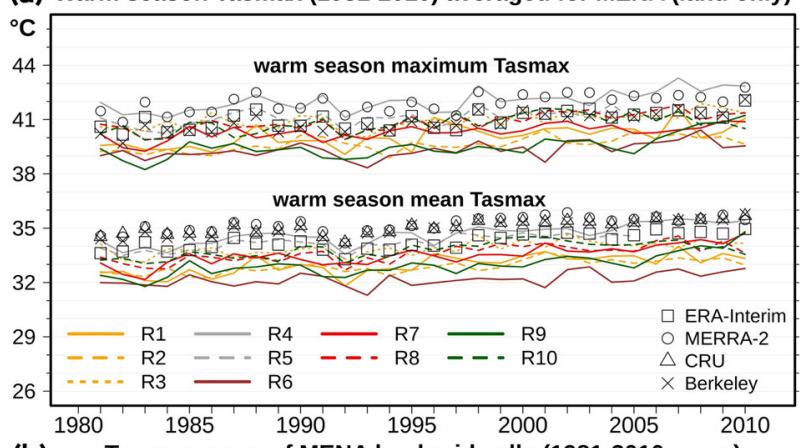

(b) Tasmax range of MENA land grid cells (1981-2010 mean)

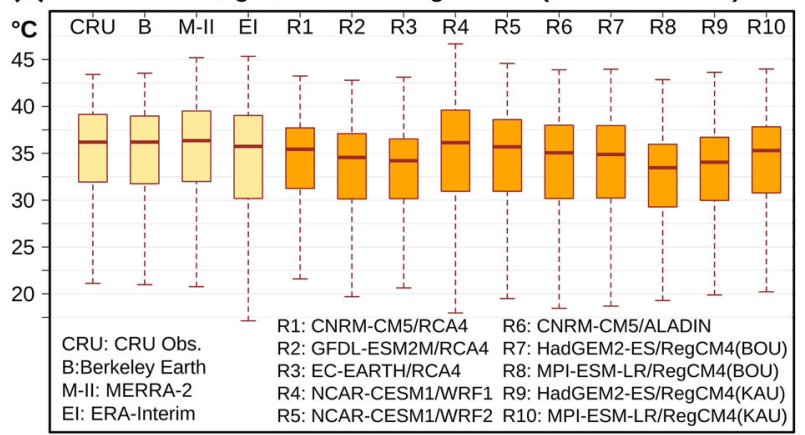

Fig. 1 Comparison with observations. Time-series of warm season (May-September) mean and maximum values of maximum daily temperature (tasmax), averaged for the MENA region (a) and ranges of warm season tasmax values for the land grid cells (b) for individual models and four reference datasets for the historical reference period 1981-2010. indicating that our assessment of heat extremes tends to be conservative and slightly underestimates the absolute extreme temperature values and thus heatwave amplitudes. This tendency is likely propagated from the driving global models that are also found to mostly underestimate tasmax (Supplementary Fig. S2). Some deviation is expected since the original spatial resolution of most reference datasets differs from the MENA-CORDEX downscaling results, while there are also differences between the reference datasets. Nevertheless, the models reproduce the observed interannual variability and positive temperature trends. The spread of tasmax values across the MENA region (in terms of 30-year climate means for the warm-season) is depicted by the box-whisker plots of Fig. 1b. The modeled medians are close to the observational and reanalysis values $\left(\sim 36^{\circ} \mathrm{C}\right)$. The tails of the boxplots represent the relatively coolest and warmest sub-regions of the MENA domain. The ranges vary between both the observed and modeled datasets.

The main spatial patterns of warm-season temperature are wellcaptured by the MENA-CORDEX ensemble mean (Supplementary Figs. S3 and S4). Nevertheless, local discrepancies and biases from observations are identified. For about $70 \%$ of the MENA land, the mean bias of the model ensemble from the gridded observations/ reanalysis is lower than $\pm 3^{\circ} \mathrm{C}$ (Supplementary Table S2). Such biases, or even higher, are typical in dynamical downscaling applications ${ }^{40,43,44}$ and are comparable to the observational uncertainty range that is found for MENA during the summer season ${ }^{45}$. Similar analysis was performed for the driving global models that are found to more strongly underestimate tasmax. A comparison between Supplementary Tables S2 and S3 indicates an overall added value and weaker biases for the dynamical downscaling. More detailed maps of the discrepancies between MENA-CORDEX simulations and the observational datasets are presented in Supplementary Figs. S5 and S6.

\section{Significance of maximum temperature projections}

To underpin the historical and future heatwaves analysis, we explored the statistical significance of the projected climate change signal. This was investigated for warm-season average and maximum tasmax by applying the Student's $t$-test. Already within the next few decades (2021-2050), the tasmax is projected to have statistically significant different sample means (at $95 \%$ confidence interval) for most areas. There is convincing consistency between the different experiments, as at least $90 \%$ of the MENA-CORDEX projections suggest significant impacts of climate change (Supplementary Fig. S7). By the end of the current century (2071-2100) and for almost every part of the region, our ensemble results indicate statistically significant changes for the daily maximum temperature. These results agree with previous studies for the region ${ }^{2,4}$. An indication of future changes, presented as MENA-averaged probability densities, is depicted in Fig. 2. The distribution of both summer average-tasmax and maximum-tasmax is projected to shift to warmer conditions. By the end of the century, the coolest summers are expected to be as hot as the hottest extremes of the historical reference period. Also, the shape of the distribution is projected to become more platykurtic, indicating more frequent seasonal extremes in the future. The simulated and projected warm-season temperature increases are consistent with the driving global models (Supplementary Fig. S8). The model spread of the EURO-CORDEX experiments is well within the spread of the corresponding global models, which are part of Phase 5 of the Coupled Model Intercomparison Project. Since the inter-model spread is similar between the results obtained by the global and regional simulations, at least some of the modeling uncertainties are not reduced through the dynamical downscaling. 

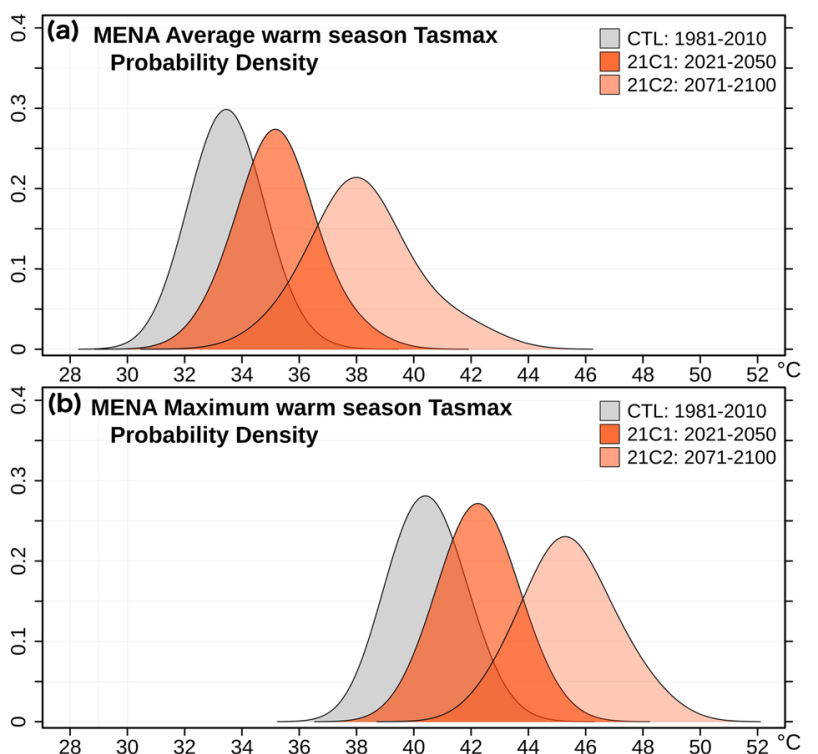

Fig. 2 Projected changes of maximum temperature. Probability density curves for simulated historical and projected future warmseason average (a) and absolute maximum (b) daily maximum temperature.

(a) Heat Wave Magnitude Index daily (HWMId)

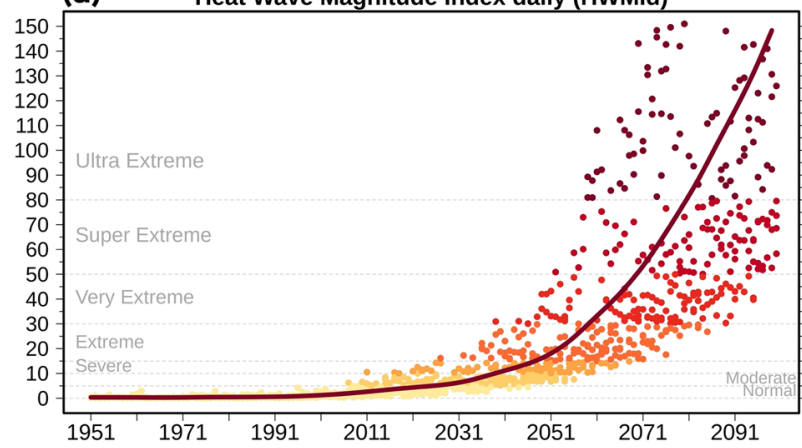

(b) \% of MENA land area exposed to heat waves

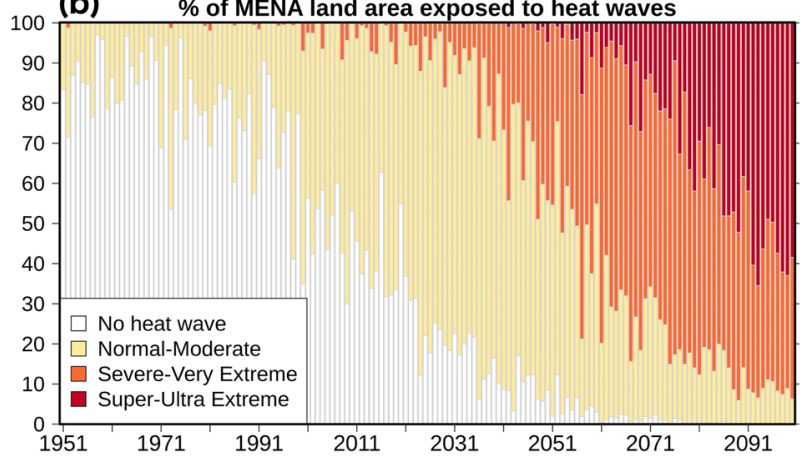

Fig. 3 (Projections of daily Heat Wave Magnitude Index). Annual values of the daily Heat Wave Magnitude (HWMId) for individual models (dots) and ensemble mean (curve) (a) and percentage of MENA land area annually exposed to several heatwave categories (b) for the period 1951-2100. Projections correspond to pathway RCP8.5.

\section{Heatwave projections}

The average daily Heat Wave Magnitude Index ${ }^{46}$ (HWMId-see "Methods" for definition) for the MENA region is presented in Fig. 3a. Each data point represents an individual year and model, while the annual ensemble mean values (smoothed) are shown by the red curve. From the beginning of the simulations until approximately the year 2020, "normal" and "moderate" heatwave conditions prevail on average. This is expected since the criteria for identifying heatwave days were based on the recent past reference period. The models, on average, suggest a transition to "severe", "extreme" and "very extreme" events by 2050-2070. For the following decades and towards the end of the 21st century, thermal conditions in the region are projected to become particularly harsh, as the so-far unobserved and thus unprecedented "super-extreme" and "ultra-extreme" events are projected to become commonplace under the "business-as-usual" Representative Concentration Pathway RCP8.5 (see "Methods" for definition of future pathways).

The spatial extent of these heatwaves is summarized in Fig. 3b. On average, up to the 1990s-2000s, $20 \%$ of the MENA land experienced "normal" to "moderate" events each year, while the remaining $80 \%$ was unaffected by heatwaves. After 2020, "severe" and "very extreme" heatwaves appear. Following the "business-asusual scenario", after mid-century the entire MENA region is projected to experience at least one "moderate", "severe" or "very extreme" event per year, while simultaneously, the unprecedented "super extreme" events start emerging. By the end of the century, high-impact "super-extreme" and "ultra-extreme" heatwaves will prevail as they are projected to affect about $60 \%$ of the region annually. While in this study we focus on the possible outcomes of RCP8.5, we have also calculated the HWMId values for the intermediate stabilization scenario RCP4.5 (Supplementary Figure 9). The comparison between the two scenarios indicates that the end-of-century HWMId values and land area exposed to heatwaves will be comparable to the mid-century of RCP8.5. For RCP4.5, by the end of the century, a small part of the MENA (up to $10 \%$ ) is expected to be exposed to "super-extreme" and "ultraextreme" heatwaves, while "severe" to "very extreme" heatwaves will become common in about $50 \%$ of the area.

The mean and maximum HWMId values for three 30-year periods are depicted in Fig. 4. For the control period, the low HWMId values indicate that, on average, "normal" heatwave events are simulated throughout the MENA region. The heatwaves with maximum magnitude are at most "moderate" (Fig. 4d), while the MENA-CORDEX ensemble indicates that "severe" heatwaves have occurred at least once in the recent past. The 30-year mean conditions in the near future (2021-2050) appear similar to the most extreme events in the control period (prevalence of "moderate" and "severe" events). The events of maximum magnitude within the next three decades fall mostly into the "extreme" or the "very extreme" categories. Towards the end of the century (2071-2100), "super-extreme" and "ultra-extreme" heat events are likely to occur at least once over most of the domain. For extended regions across the Arabian Peninsula, northern and sub-Saharan Africa "ultra-extreme" heatwaves, as defined by present-day criteria, will become the normal (Fig. 4c, f).

The modeled mean duration of heatwaves, averaged over 30year climatic periods, is presented in Fig. $5(\mathrm{a}-\mathrm{c})$. Only years with heatwave occurrence were considered in this part of the analysis. According to the MENA-CORDEX ensemble for the control period, when heatwaves occur, they last on average 4-6 days (Fig. 5a). Individual high-impact events are simulated to last up to two weeks, mainly for inland locations (Supplementary Fig. S10). For the near future (2021-2050), the average duration of heatwaves increases and can even exceed ten days in some locations (Fig. $5 b)$. The longest duration events in this period are projected to continue for more than a month, i.e., in hot-spots of North Africa and the Arabian Peninsula. The end-of-the-century projections of heatwaves suggest prolonged events lasting several weeks (Fig. $5 c)$. For the more temperate Mediterranean coastal area, the average heatwave duration is expected to be between two and three weeks. For the warmer parts of North Africa and the Arabian Peninsula, extreme heatwaves (today's criteria) are on average 

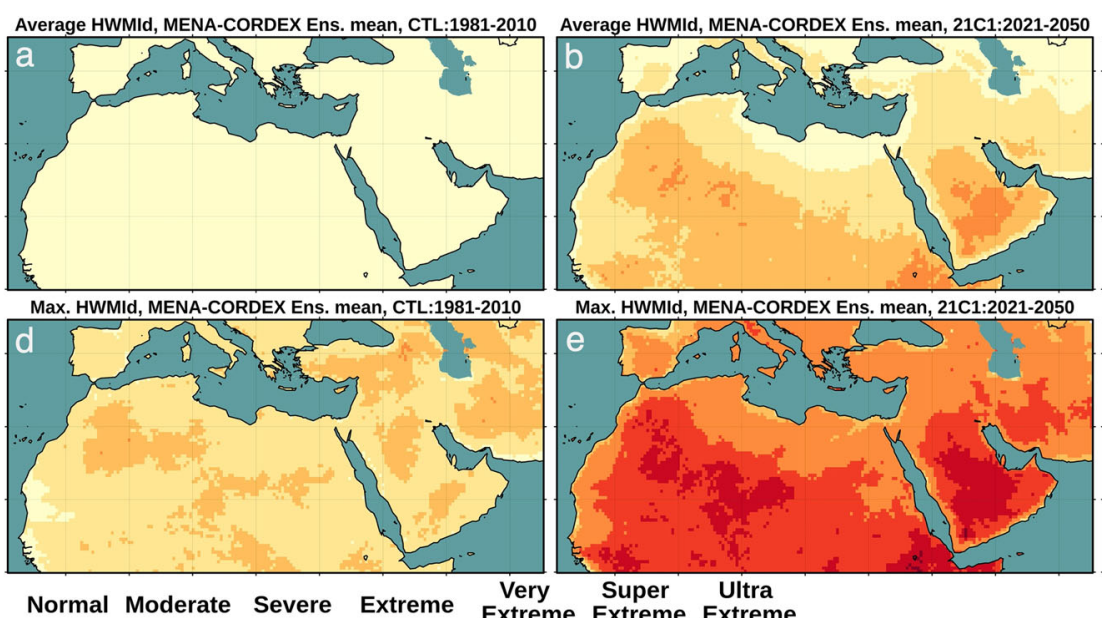

MX. HWMId, MENA-CORDEX Ens. mean, 21C1:2021-2050

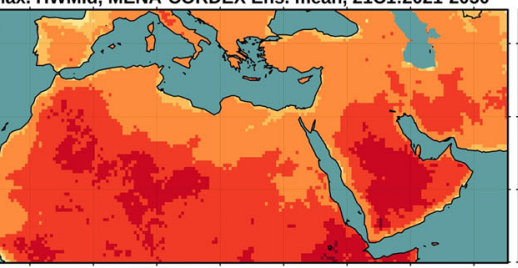

Super Ultra

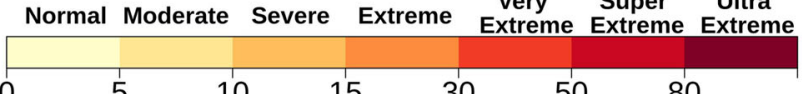

$50 \quad 80$

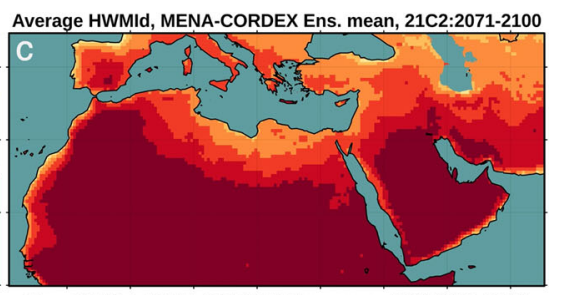

Max. HWMId, MENA-CORDEX Ens. mean, 21C2:2071-2100

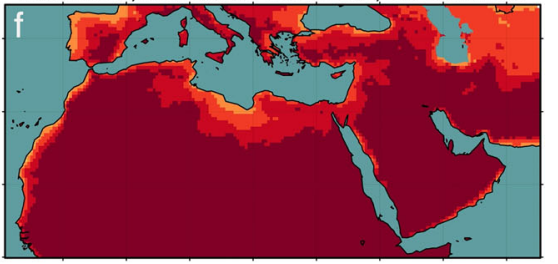

Fig. 4 Maps of daily Heat Wave Magnitude Index. Average (a-c) and absolute maximum (d-f) Heat Wave Magnitude Index daily (HWMId) values for the control reference period (CTL: 1981-2010), the near future (21C1: 2021-2050) and the end of the 21st century (21C2: 2071-2100) based on pathway RCP8.5.

projected to last between one to two months or even longer in some of the above-mentioned locations. Under RCP8.5 and for exceptionally warm years, the duration of heatwaves is projected to be even longer (Supplementary Fig. S10).

The amplitude of heatwaves, defined as the peak temperature of the hottest day during an event, is presented in Fig. 5(d-i) as average and maximum values for each 30 -year period. As for the heatwave duration, only years with heatwave occurrence were considered in the calculation of the 30-year averages. For the historical reference period, average heatwaves have a peak temperature (ensemble mean) that ranges from $20^{\circ} \mathrm{C}$ for the highest mountainous regions of the MENA to $50^{\circ} \mathrm{C}$ in the hottest areas near the Arabian Gulf. The absolute maximum heatwave amplitudes of the $1981-2010$ hottest events are about $3^{\circ} \mathrm{C}$ warmer than the average amplitudes throughout the domain (Fig. $5 \mathrm{~g}$ ). For the following decades and for the 2021-2050 period, heatwave amplitudes are expected to increase by $0.5-2{ }^{\circ} \mathrm{C}$ on average, while the hottest events in this period are projected to be $3{ }^{\circ} \mathrm{C}$ warmer than in the reference period (Fig. 5h). By the end of the century, under the high greenhouse gas emission pathway, the maximum temperature during heatwaves is expected to exceed $56^{\circ} \mathrm{C}$ in the warmest parts of the MENA region (Fig. 5i). As mentioned above, our model ensemble slightly underestimates tasmax, therefore these can be considered to be conservative estimates. Maximum temperatures are also likely to be higher in densely populated and urbanized areas due to the fact that climate models do not account for the urban heat island effect.

Regarding frequency, the MENA-CORDEX ensemble for the reference period (Fig. $6 \mathrm{a}, \mathrm{d}, \mathrm{g}$ ) simulates between 6 and 15 "normal" or "moderate" events per 30 years. The maximum of 15 events per 30 years (or 1 event every 2 years) is found in the Levant and in the central part of the MENA region, which is however only sparsely populated. A limited number of "severe", "extreme" or "very extreme" events (between 1 and 3) were simulated throughout the domain, while in the historic simulations "super-extreme" and "ultra-extreme" heatwaves did not occur. For the coming decades (2021-2050) the frequency of "normal" or "moderate" events increases to more than 20 events per 30 years, mainly in the more densely populated coastal regions. For the warmer inland regions of North Africa and the Arabian Peninsula, "severe", "extreme" or "very extreme" events are becoming more frequent as they are expected to occur up to 15-20 times in the 30-year period. In the hotter parts of the domain, "super-extreme" and "ultra-extreme" heatwaves start to emerge; however, their occurrence is still rare (1-3 events per 30 years). For the 2071-2100 period (Fig. 6c, f, i), "normal" or "moderate" events are projected to occur regularly only in the coastal regions. This is mainly due to the moderating temperature effect of the seas, which warm more slowly than the continental areas (not shown). The frequency of "severe", "extreme" or "very extreme" is projected to increase to at least one event every two years in the inland areas, while higher frequencies are projected towards the coasts. By the end of the century, the high-impact "super-extreme" and "ultra-extreme" events may occur at least once during this 30-year period in every grid cell of the MENA domain. In the hottest regions, their frequency will become much higher and events of such magnitude are expected to occur almost every year.

\section{Human population exposure to heatwaves}

The human population of the MENA region (including the Mediterranean and southern Europe) is currently about one billion people, of which about $60 \%$ lives in cities (Fig. 7). The narrative of the corresponding Shared Socioeconomic Pathway (SSP5) implies a strong population increase until 2060-2070s and then a decrease until the year 2100 (see Methods). Urbanization is projected to continue, and by the end of the century more than $90 \%$ of the MENA inhabitants are expected to be urban dwellers. Currently, according to the SSP5 projections, about half of the regional population is exposed to "normal" or "moderate" heatwaves annually. Nowadays, "severe", "extreme", and "very extreme" events are affecting a few million people each year. This number is projected to peak around the year 2065 and then decrease. The unprecedented "super-extreme" and "ultraextreme" heatwaves start to affect a significant portion of the MENA population by 2060 (more than 100 million), which continues to increase in the following decades. By the end of the 21 st century, about 600 million inhabitants or about $50 \%$ of the population of the region may be exposed to "super-extreme" and "ultra-extreme" events. Another $\mathbf{4 0 0}$ million is projected to be exposed to weaker, but still high-impact, "severe", "extreme" and "very extreme" events at least once each year. The majority of people is anticipated to live in large urban conglomerates that are expected to expand both in terms of spatial extent and population density. This will result in a stronger UHI effect, which will consequently induce additional heat stress. This effect is not 

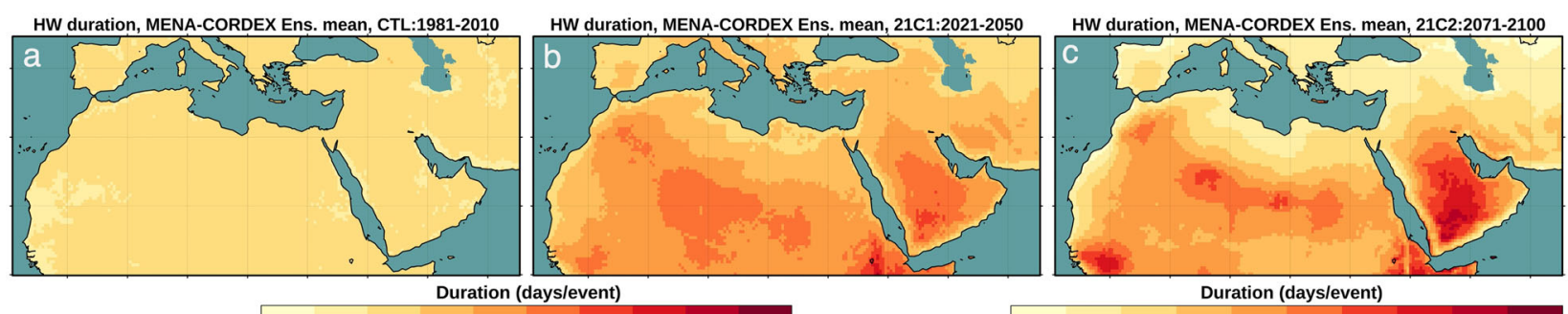

Duration (days/event)
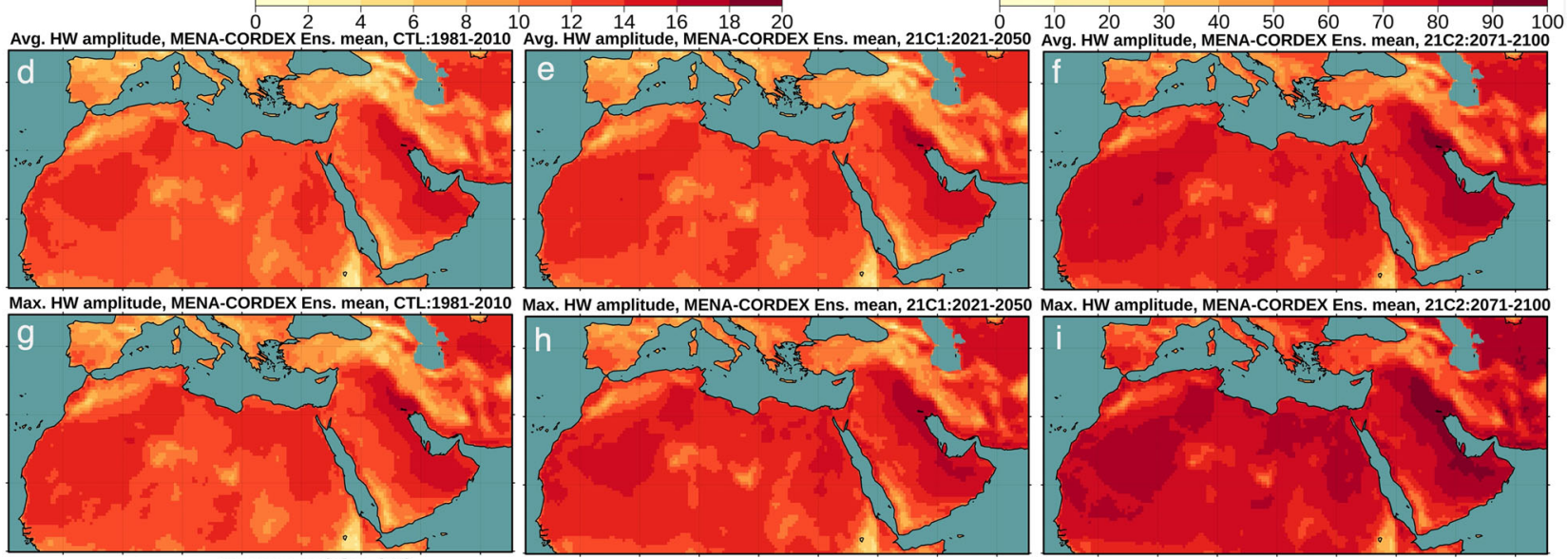

Degrees Celsius $\left({ }^{\circ} \mathrm{C}\right)$

\begin{tabular}{|l|l|l|l|l|l|l}
\hline 20.5 & 26.5 & 32.5 & 38.5 & 44.5 & 50.5 & 56.5
\end{tabular}

Fig. 5 Heatwave duration and amplitude. Average heatwave duration (a-c), average amplitude (d-f) and absolute maximum amplitude (g-i) for the control reference period (CTL: 1981-2010), the near future (21C1: 2021-2050), and the end of the 21st century (21C2: 2071-2100) based on pathway RCP8.5.

considered here, since city scales are not adequately resolved in climate models, while the influence of the UHI effect can vary significantly depending on the urban canopy (e.g., albedo, orientation, thermal properties, etc.) and local flow conditions, which should be taken into account in mitigation and adaptation strategies.

\section{DISCUSSION}

In this study, we explored an ensemble of MENA-CORDEX regional climate projections under a strong radiative forcing pathway (RCP8.5). Our multi-model assessment for the region indicates a future transition to extreme heatwave conditions in the future, with unprecedented "super-extreme" and "ultra-extreme" events that start to appear by mid-century and could become common summer conditions by the end of the century. Future events of such extraordinary duration, amplitude, and frequency will impose conditions that will challenge human health and societies with profound impacts on livestock, agriculture, and biodiversity. For the Mediterranean part of the MENA domain, our results agree with HWMId values and conclusions presented by Molina et al. ${ }^{47}$. Their study was based on higher-resolution EURO-CORDEX projections. The strong heating over the region and the transition to hotter conditions is mainly driven by the intensification of the greenhouse effect due to unabated anthropogenic emissions and land-use changes. Previous analysis suggested that the exceptional summertime warming is associated with a thermal low, which is conceived as a widening of the Persian trough that extends from South Asia to the eastern Mediterranean, and is projected to expand westward and combine with the intensifying thermal low over the Sahara ${ }^{4}$. Amplifying feedbacks such as landatmosphere interactions and expanding soil moisture deficits are also partly responsible for the relatively strong warm-season heating ${ }^{48}$.
Peak temperatures during future heatwaves could exceed $56{ }^{\circ} \mathrm{C}$ in some locations in the Middle East, and our analysis indicates that this is a conservative estimate. This will be life-threatening for humans, and even high-temperature tolerant animals such as camels cannot survive in such conditions. The exposed human population is expected to be concentrated in large urban centers. Due to the UHI effect, the temperature maxima during such events is expected to be even higher in the built environment and especially in megacities. Due to spatial resolution limitations and the lack of information about the present and future cities this effect is not considered in our projections. Taking moderate UHI intensities ${ }^{49,50}$ into account, we anticipate that the maximum temperature during "super-extreme" and "ultra-extreme" heatwaves in some urban centers and megacities in the MENA could reach or even exceed $60^{\circ} \mathrm{C}$, which would be tremendously disruptive for society. Humanity in such locations will depend on indoor and outdoor cooling or will be forced to migrate.

Here, we focussed on the business-as-usual pathway (RCP8.5) and considered the intermediate RCP4.5 conditions for comparison. Our aim is also to also investigate future heatwave conditions under less pessimistic scenarios (e.g., RCP2.6), however, the currently available model ensemble is limited by the small number of simulations. For the pathway RCP4.5, the end-ofcentury summer maximum temperature conditions will be comparable to those of the mid-century for RCP8.5, while the mid-century heatwave conditions from both scenarios are only marginally different. The comparison between these two future pathways indicates that while the RCP4.5 conditions may be less massively disruptive, they will nevertheless have severe impacts on public health and society. The obvious conclusion is that implementation of mitigation and adaptation measures must be realized with high priority in the coming decades, and that the MENA countries need to prepare for exceedingly hot summers. 

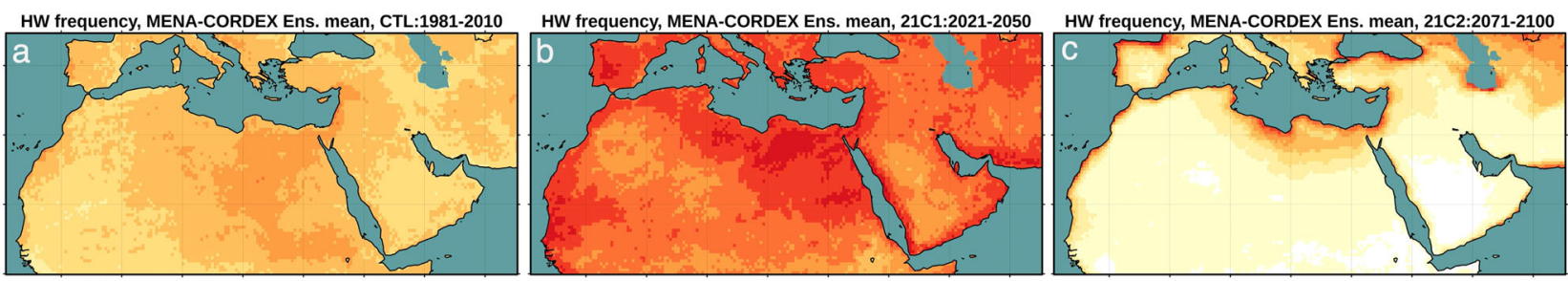

Number of normal \& moderate events in 30 years
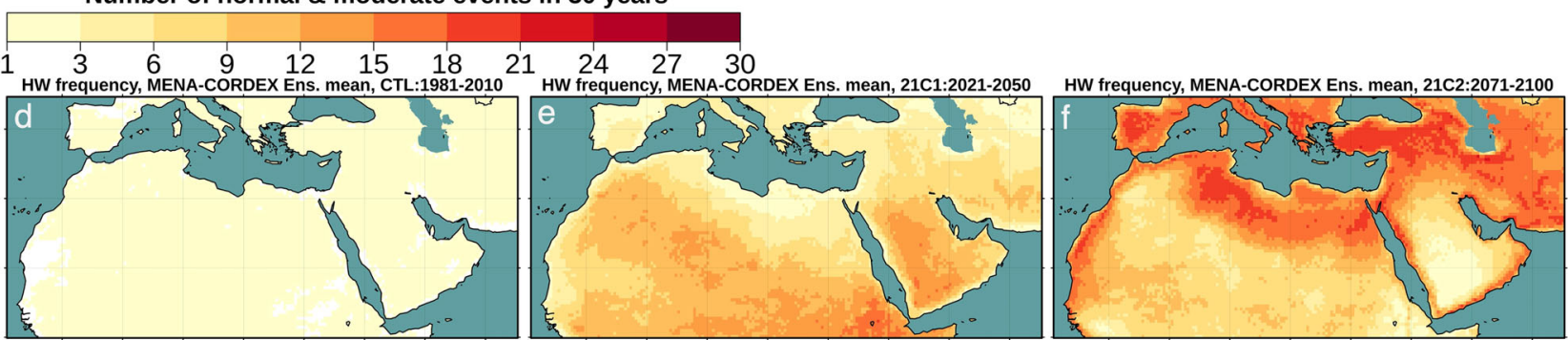

Number of severe,extreme \& very extreme events in 30 years
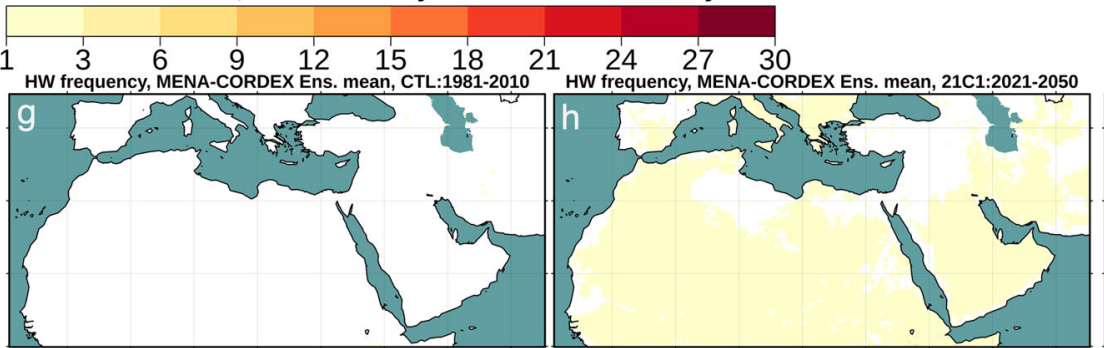

Number of super \& ultra extreme events in 30 years

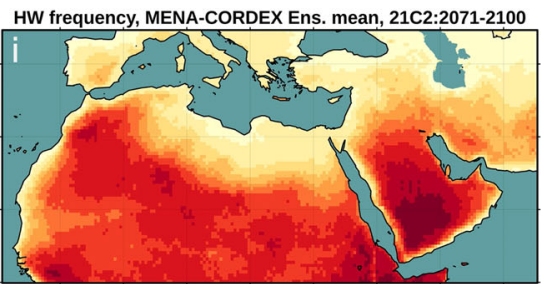

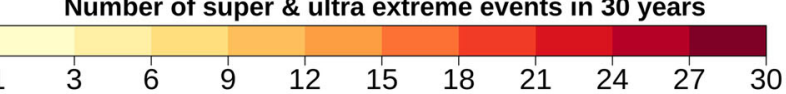

Fig. 6 Heatwave frequency. Frequency of normal or moderate events $(\mathbf{a}-\mathbf{c})$, severe, extreme or very extreme events (d-f), and super-extreme or ultra-extreme events (g-i) for the historical reference period (CTL: 1981-2010), the near future (21C1: 2021-2050) and the end of the 21st century (21C2: 2071-2100) based on pathway RCP8.5. White areas indicate no occurrence of heatwave events of a specific class.

MENA total and exposed to heatwaves population (in millions)

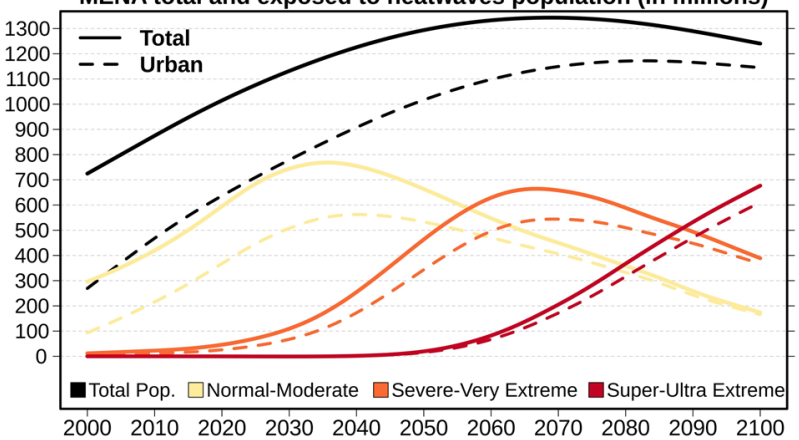

Fig. 7 Population exposure to heatwaves. Total MENA population according to the SSP5 narrative and population that is projected to be exposed to events with heatwave events of various magnitudes. Solid curves represent the total and dashed curves the urban population.

\section{METHODS}

\section{Climate data and projections}

We analyzed a multi-model ensemble of ten MENA-CORDEX simulations (Supplementary Table S1). Our ensemble is the result of combining six global earth system models and four regional climate models. All dynamical downscaling simulations follow the general CORDEX guidelines ${ }^{51}$. Future climate projections $(2006-2100)$ are presented for the "business-as-usual" Representative Concentration Pathway RCP8.5 ${ }^{52}$. Analysis of the intermediate RCP4.5 was also performed and is presented in the Supplementary Information. The horizontal resolution of the first phase of CORDEX for this region was set at $0.44^{\circ}(\sim 50 \mathrm{~km})$, and the full extent of the domain is presented in Supplementary Fig. S1. While the larger African domain is needed to model the atmospheric dynamics, e.g., of the monsoon circulations, here we focus on the MENA region with a predominantly subtropical climate, and we excluded the area south of $10^{\circ} \mathrm{N}$, as well as regions that extent across the eastern and the western boundaries, indicated by the white rectangle in Figure S1. For most of the numerical experiments, we analyzed the daily maximum temperature data series for the period 1951-2100. However, the temporal data availability can vary slightly (Supplementary Table S1). As a baseline control reference period, we defined the historical 30-year period of 1981-2010. The last 5 years (2006-2010) are part of the RCP8.5. projections, which are however found to closely follow the observed trends ${ }^{2}$. For the data analysis and visualization, we defined two future periods of equal duration, one representing the near-future climate (21C1: 2021-2050) and one for the end of the century (21C2: 2071-2100).

For model evaluation, we focus on the daytime maximum temperature during the warm season, defined here as the 5-month period from May to September. Simulated mean values and absolute maxima during this season are compared with gridded observations. Our reference datasets include the latest version (v4.04) of the Climate Research Unit (CRU) gridded observations $s^{53}$ and the Berkeley Earth dataset ${ }^{54}$. For our application, these two datasets are found to have some limitations. The former (CRU), while having a spatial resolution of $0.5^{\circ}$ which is comparable to the MENA-CORDEX domain, only provides monthly temporal resolution. The latter dataset (Berkeley Earth) is daily but has a coarser horizontal resolution $\left(1^{\circ} \times 1^{\circ}\right)$. Therefore, we complemented our reference datasets with daily reanalysis products of ERA-Interim ${ }^{55}$ and MERRA-2 ${ }^{56}$. For MENAaveraged time series comparison, spatial maps, and quantitative bias assessment we utilized all four available observational and reanalysis datasets. Land-only maximum daily temperatures were remapped using bilinear interpolation to the MENA-CORDEX model grid. 


\section{Heatwave definition and calculations}

According to the World Meteorological Organization, there is no universally accepted definition of heatwaves (https://www.wmo.int/ $\mathrm{pages} / \mathrm{prog} / \mathrm{wcp} / \mathrm{ccl} /$ references). Several definitions, metrics, and indices have been proposed in the literature and are used by the meteorological services and other authorities. Some of these definitions are based on local criteria and absolute thresholds of temperature, while others are calculated on percentage-based standards or they also include additional variables such as relative humidity or planetary boundary layer height ${ }^{5,6,57}$ Following Russo et al. $^{58}$, we defined a heatwave as a period of at least three consecutive days with a maximum temperature above a daily percentage-based threshold. This is the 90th percentile of daily maxima (centered on a 31-day window), based on simulated data for the recent past reference period (1981-2010). Here, we refined it to the 95th percentile to match the leptokurtic nature of the temperature distribution that is common in the MENA region ${ }^{6}$. Such a percentage-based definition can be universally applied on a global scale or to extended regions such as the one under investigation. Another advantage of such percentage-based definitions is that the effect of biases that are eventually introduced by global or regional climate models is minimized.

To assess the intensity of a particular event, we used the daily Heat Wave Magnitude Index (HWMld) introduced and optimized by Russo et al. ${ }^{46,58}$ This comprehensive index of heatwave magnitude sums excess temperatures beyond a certain normalized threshold and combines both the duration and temperature anomalies of intense heatwaves in a single indicator $^{14}$. Following the identification of heatwave days (described in the previous section), the daily heatwave magnitude (Md) is calculated as follows:

$M_{d}\left(T_{d}\right)=\left\{\begin{array}{l}\frac{T d-T_{30025 \mathrm{p}}}{T_{30 \mathrm{y} 75 \mathrm{p}}-T_{30 \mathrm{y} 25 \mathrm{p}}} \text { if } T_{d}>T_{30 \mathrm{y} 25 \mathrm{p}} \\ 0 \text { if } T_{d} \leq T_{30 \mathrm{y} 25 \mathrm{p}}\end{array}\right.$

with $T d$ being the maximum daily temperature at the surface (tasmax) on day $d$ of the heatwave, T30y25p and T30y75p are the 25th and 75th percentile values respectively of the time series composed of 30 annual tasmax values within the reference period 1981-2010. The interquartile range (IQR) of the daily tasmax is used as the heatwave magnitude unit, since it represents a non-parametric measure of the variability of the timeseries. According to this definition, an indicative Md value of 2 means that the temperature anomaly on that day is twice the IQR. Finally, HWMId is the sum of the daily magnitude of the consecutive days of the most severe heatwave for each year. The calculation of HWMId is performed on a gridcell level with the full extent of available time-series for each ensemble member being considered.

A descriptive classification of heatwave events based on the HWMId values was proposed by Russo et al. $^{58}$ and is presented in Table 1. To help interpret the heatwave index, Table 2 presents several past events. In addition to the heatwave magnitude, several other characteristics are considered. Heatwave duration is defined as the duration (in days) of the most severe heatwave per year. Furthermore, we introduce the notion of heatwave amplitude, defined as the peak daily temperature of the maximum HWMId event for each year (in ${ }^{\circ} \mathrm{C}$ ).

\section{Population data and projections}

The proportion of the population that may become exposed to extreme thermal conditions in the MENA region was calculated by combining the future HWMId estimates with gridded global population projections for the 21 st century, based on the Shared Socioeconomic Pathways or SSPs ${ }^{59}$. Of the five qualitative descriptions of SSPs ${ }^{60}$, only SSP5 ("Fossil-fuelled Development-Taking the Highway") projects radiative forcing at levels as high as RCP8.5. SSP5 implies major challenges to mitigation and low challenges to adaptation. According to this pathway, the global (and MENA) population size is expected to peak near 2050 and then starts to decline. Although the absolute global and regional population numbers are not the highest among the range of possible SSP scenarios, SSP5 is the pathway with the highest percentage of urban population. We explored the numbers of both total (= urban + rural) and urban population that may be exposed to severe heatwave conditions for each year. The original gridded population data are available for the period 2000-2100 at 10-year intervals and on a spatial grid of $1 \mathrm{~km}^{61}$. To combine the population data with the MENA-CORDEX model grid we (spatially) aggregated the population grids onto an intermediate grid (with a spacing similar to the target grid), before applying the nearest-neighbor resampling algorithm to match the MENA-CORDEX grid. This procedure was necessary to ensure
Table 1. Levels of daily Heat Wave Magnitude Index (HWMId).

\begin{tabular}{llll}
\hline HWMId & Heatwave category & HWMId & Heatwave category \\
\hline 0 & No Heat Wave & $15-30$ & Extreme \\
$0-5$ & Normal & $30-50$ & Very extreme \\
$5-10$ & Moderate & $50-80$ & Super extreme \\
$10-15$ & Severe & $>80$ & Ultra-extreme \\
\hline
\end{tabular}

Table 2. HWMId values for nine observed historical events (adopted from Russo et al. ${ }^{46}$ ) and classification of them into heatwave (HW) categories according to Table 1.

\begin{tabular}{llll}
\hline Year & Location & HWMld & HW category \\
\hline 2010 & Russia & 71.9 & Super extreme \\
2003 & Central Europe & 44.7 & Very extreme \\
1972 & Finland & 38.2 & Very extreme \\
1976 & United Kingdom & 35.8 & Very extreme \\
1969 & Norway & 26.5 & Extreme \\
2015 & Central Europe & 26 & Extreme \\
2007 & Greece & 22.9 & Extreme \\
1994 & Benelux & 21.3 & Extreme \\
2014 & Scandinavia & 21.2 & Extreme \\
\hline
\end{tabular}

that the total population numbers are conserved. We then applied a linear time interpolation at each grid point to create annual population numbers, assuming that there are no abrupt population changes within the ten-year periods.

\section{DATA AVAILABILITY}

Regional climate model data from SMHI-RCA4, BOUN-RegCM4, and CYI-WRF regional experiments are publicly available through the Earth System Grid Federation data portals (https://esg-dn1.nsc.liu.se/search/esgf-liu/). The rest of the data that support the findings of this study are available from the authors upon request.

\section{CODE AVAILABILITY}

Analysis was performed using the R Project for Statistical Computing (https://www.rproject.org/). HWMId calculations were based on R Package "extRemes" (https://cran. r-project.org/web/packages/extRemes/extRemes.pdf). Codes are available upon request.

Received: 30 October 2020; Accepted: 25 February 2021; Published online: 23 March 2021

\section{REFERENCES}

1. IPCC. Climate Change 2013: The Physical Science Basis. Contribution of Working Group I to the Fifth Assessment Report of the Intergovernmental Panel on Climate Change. (Cambridge University Press, 2013).

2. Zittis, G., Hadjinicolaou, P., Klangidou, M., Proestos, Y. \& Lelieveld, J. A multimodel, multi-scenario, and multi-domain analysis of regional climate projections for the Mediterranean. Reg. Environ. Chang. 19, 2621-2635 (2019).

3. Almazroui, M., Saeed, F. \& Saeed, S. Projected change in temperature and precipitation over Africa from CMIP6. Earth Syst. Environ. (2020).

4. Lelieveld, J. et al. Strongly increasing heat extremes in the Middle East and North Africa (MENA) in the 21st century. Clim. Change 137, 245-260 (2016).

5. Fischer, E. M. \& Schär, C. Consistent geographical patterns of changes in highimpact European heatwaves. Nat. Geosci. 3, 398-403 (2010).

6. Zittis, G., Hadjinicolaou, P., Fnais, M. \& Lelieveld, J. Projected changes in heat wave characteristics in the eastern Mediterranean and the Middle East. Reg. Environ. Chang. 16, 1863-1876 (2016). 
7. Legasa, M. N. et al. Assessing multi-domain overlaps and grand ensemble generation in CORDEX regional projections. Geophys. Res. Lett. 47, (2020).

8. El-Samra, R., Bou-Zeid, E., Bangalath, H. K., Stenchikov, G. \& El-Fadel, M. Seasonal and regional patterns of future temperature extremes: high-resolution dynamic downscaling over a complex terrain. J. Geophys. Res. Atmos. 123, 6669-6689 (2018).

9. Kuglitsch, F. G. et al. Heat wave changes in the eastern Mediterranean since 1960. Geophys. Res. Lett. 37, L04802 (2010).

10. Almazroui, M., Islam, M. N., Dambul, R. \& Jones, P. D. Trends of temperature extremes in Saudi Arabia. Int. J. Climatol. 34, 808-826 (2014).

11. Donat, M. G. et al. Changes in extreme temperature and precipitation in the Arab region: long-term trends and variability related to ENSO and NAO. Int. J. Climatol. 34, 581-592 (2014).

12. Tanarhte, M., Hadjinicolaou, P. \& Lelieveld, J. Heat wave characteristics in the eastern Mediterranean and Middle East using extreme value theory. Clim. Res. 63, 99-113 (2015).

13. Filahi, S., Tanarhte, M., Mouhir, L., El Morhit, M. \& Tramblay, Y. Trends in indices of daily temperature and precipitations extremes in Morocco. Theor. Appl. Climatol. 124, 959-972 (2016).

14. Ceccherini, G., Russo, S. \& Ameztoy, I. Heat waves in Africa 1981-2015, observations and reanalysis. Nat. Hazards Earth Syst. Sci. 17, 115-125 (2017).

15. Giannaros, T. M., Kotroni, V., Lagouvardos, K. \& Matzarakis, A. Climatology and trends of the Euro-Mediterranean thermal bioclimate. Int. J. Climatol. 38, 3290-3308 (2018).

16. El Kenawy, A. M. et al. Daily temperature extremes over Egypt: spatial patterns, temporal trends, and driving forces. Atmos. Res. 226, 219-239 (2019).

17. Fontaine, B., Janicot, S. \& Monerie, P. A. Recent changes in air temperature, heat waves occurrences, and atmospheric circulation in Northern Africa. J. Geophys. Res. Atmos. 118, 8536-8552 (2013).

18. Habib, R. R., El, Z. K. \& Ghanawi, J. Climate change and health research in the Eastern Mediterranean Region. Ecohealth 7, 156-175 (2010).

19. Ahmadalipour, A. \& Moradkhani, H. Escalating heat-stress mortality risk due to global warming in the Middle East and North Africa (MENA). Environ. Int. 117, 215-225 (2018).

20. Constantinidou, K., Hadjinicolaou, P., Zittis, G. \& Lelieveld, J. Effects of climate change on the yield of winter wheat in the eastern Mediterranean and Middle East. Clim. Res. 69, 129-141 (2016).

21. Zachariadis, T. \& Hadjinicolaou, P. The effect of climate change on electricity needs-a case study from Mediterranean Europe. Energy 76, 899-910 (2014).

22. Lange, M. A. Impacts of climate change on the Eastern Mediterranean and the Middle East and North Africa region and the water-energy nexus. Atmosphere 10, 455 (2019).

23. Dunne, J. P., Stouffer, R. J. \& John, J. G. Reductions in labour capacity from heat stress under climate warming. Nat. Clim. Chang. 3, 563-566 (2013).

24. Abel, G. J., Brottrager, M., Crespo Cuaresma, J. \& Muttarak, R. Climate, conflict and forced migration. Glob. Environ. Chang. 54, 239-249 (2019).

25. United Nations Economic and Social Commission for Western Asia (ESCWA) et al. Arab Climate Change Assessment Report-Main Report (2017).

26. McGeehin, M. A. \& Mirabelli, M. The potential impacts of climate variability and change on temperature-related morbidity and mortality in the United States. Environ. Health Perspect. 109, 185-189 (2001).

27. Pal, J. S. \& Eltahir, E. A. B. Future temperature in southwest Asia projected to exceed a threshold for human adaptability. Nat. Clim. Chang. 6, 197-200 (2016).

28. Almazroui, M. Summer maximum temperature over the gulf cooperation council states in the twenty-first century: multimodel simulations overview. Arab J. Geosci. 9, 13 (2020).

29. Kang, S., Pal, J. S. \& Eltahir, E. A. B. Future heat stress during Muslim pilgrimage (Hajj) projected to exceed "Extreme Danger" levels. Geophys. Res. Lett. 46, 10094-10100 (2019).

30. Waha, K. et al. Climate change impacts in the Middle East and Northern Africa (MENA) region and their implications for vulnerable population groups. Reg. Environ. Chang. 17, 1623-1638 (2017).

31. Jiang, L. \& O"Neill, B. C. Global urbanization projections for the shared socioeconomic. Pathw. Glob. Environ. Chang. 42, 193-199 (2017).

32. Li, D. \& Bou-Zeid, E. Synergistic interactions between urban heat islands and heat waves: the impact in cities is larger than the sum of its parts. J. Appl. Meteorol. Climatol. 52, 2051-2064 (2013).

33. Zittis, G., Hadjinicolaou, P. \& Lelieveld, J. Comparison of WRF model physics parameterizations over the MENA-CORDEX domain. Am. J. Clim. Chang. 03, 490-511 (2014).

34. Almazroui, M. RegCM4 in climate simulation over CORDEX-MENA/Arab domain: selection of suitable domain, convection and land-surface schemes. Int. J. Climatol. 36, 236-251 (2016).

35. Almazroui, M. et al. Simulation of temperature and precipitation climatology for the CORDEX-MENA/Arab domain using RegCM4. Arab J. Geosci. 9, 1-14 (2016).
36. Bucchignani, E., Cattaneo, L., Panitz, H. J. \& Mercogliano, P. Sensitivity analysis with the regional climate model COSMO-CLM over the CORDEX-MENA domain. Meteorol. Atmos. Phys. 128, 73-95 (2016).

37. Bucchignani, E., Mercogliano, P., Rianna, G. \& Panitz, H. J. Analysis of ERA-Interimdriven COSMO-CLM simulations over Middle East-North Africa domain at different spatial resolutions. Int. J. Climatol. 36, 3346-3369 (2016).

38. Zittis, G. \& Hadjinicolaou, P. The effect of radiation parameterization schemes on surface temperature in regional climate simulations over the MENA-CORDEX domain. Int. J. Climatol. 37, 3847-3862 (2017).

39. Constantinidou, K., Hadjinicolaou, P., Zittis, G. \& Lelieveld, J. Sensitivity of simulated climate over the MENA region related to different land surface schemes in the WRF model. Theor. Appl. Climatol. 141, 1431-1449 (2020).

40. Bucchignani, E., Mercogliano, P., Panitz, H. J. \& Montesarchio, M. Climate change projections for the Middle East-North Africa domain with COSMO-CLM at different spatial resolutions. Adv. Clim. Chang. Res. 9, 66-80 (2018).

41. Ozturk, T., Turp, M. T., Türkeş, M. \& Kurnaz, M. L. Future projections of temperature and precipitation climatology for CORDEX-MENA domain using RegCM4.4. Atmos. Res. 206, 87-107 (2018).

42. Driouech, F., Elrhaz, K. \& Moufouma, W. Assessing future changes of climate extreme events in the CORDEX-MENA region using regional climate model ALADIN-climate. Earth Syst. Environ. 4, 477-492 (2020).

43. Tanarhte, M., Hadjinicolaou, P. \& Lelieveld, J. Intercomparison of temperature and precipitation data sets based on observations in the Mediterranean and the Middle East. J. Geophys. Res. Atmos. 117, D12102 (2012).

44. Katragkou, E. et al. Regional climate hindcast simulations within EURO-CORDEX: evaluation of a WRF multi-physics ensemble. Geosci. Model Dev. 8, 603-618 (2015).

45. Kotlarski, S. et al. Regional climate modeling on European scales: a joint standard evaluation of the EURO-CORDEX RCM ensemble. Geosci. Model. Dev. 7, 1297-1333 (2014).

46. Russo, S., Sillmann, J. \& Fischer, E. M. Top ten European heatwaves since 1950 and their occurrence in the coming decades. Environ. Res Lett. 10, 124003 (2015).

47. Molina, M. O., Sánchez, E. \& Gutiérrez, C. Future heat waves over the Mediterranean from an Euro-CORDEX regional climate model ensemble. Sci. Rep. 10, 8801 (2020).

48. Zittis, G., Hadjinicolaou, P. \& Lelieveld, J. Role of soil moisture in the amplification of climate warming in the eastern Mediterranean and the Middle East. Clim. Res. 59, 27-37 (2014).

49. Santamouris, M. Analyzing the heat island magnitude and characteristics in one hundred Asian and Australian cities and regions. Sci. Total Environ. 513, 582-598 (2015).

50. Zhao, L. et al. Global multi-model projections of local urban climates. Nat. Clim. Chang. 11, 152-157 (2021).

51. Giorgi, F. \& Gutowski, W. J. Coordinated experiments for projections of regional climate change. Curr. Clim. Chang. Rep. 2, 202-210 (2016).

52. Riahi, K., Rao, S. \& Krey, V. RCP 8.5-A scenario of comparatively high greenhouse gas emissions. Clim. Change 109, 33-57 (2011).

53. Harris, I. et al. Version 4 of the CRU TS monthly high-resolution gridded multivariate climate dataset. Sci. Data 7, 109 (2020).

54. Rohde, R. et al. Berkeley earth temperature averaging process. Geoinform. Geostat. Overv. 1, 2 (2013).

55. Dee, D. P. et al. The ERA-Interim reanalysis: configuration and performance of the data assimilation system. Q. J. R. Meteorol. Soc. 137, 553-597 (2011).

56. Gelaro, R. et al. The modern-era retrospective analysis for research and applications, version 2 (MERRA-2). J. Clim. 5419-5454 (2017).

57. Hochman, A., Scher, S. \& Quinting, J. A new view of heat wave dynamics and predictability over the Eastern Mediterranean. Earth Syst. Dyn. 12, 133-149 (2020).

58. Russo, S. et al. Magnitude of extreme heat waves in present climate and their projection in a warming world. J. Geophys. Res. Atmos. 119, 12500-12512 (2014).

59. Gao, J. Downscaling global spatial population projections from 1/8-degree to 1km grid cells. NCAR Technical Note, NCAR/TN-537+STR (2017).

60. Riahi, K. et al. The Shared Socioeconomic Pathways and their energy, land use, and greenhouse gas emissions implications: an overview. Glob. Environ. Chang. 42, 153-168 (2017).

61. Gao, J. Global 1-km downscaled population base year and projection grids based on the shared socioeconomic pathways, revision 01. (NASA Socioeconomic Data and Applications Center-SEDAC (2020). https://doi.org/10.7927/q7z9-9r69. Accessed 03 Feb 2021.

\section{ACKNOWLEDGEMENTS}

This research was supported by the EMME-CARE project that has received funding from the European Union's Horizon 2020 Research and Innovation Program, under Grant Agreement No. 856612, as well as matching co-funding by the Government of 
the Republic of Cyprus. It was co-funded by the European Regional Development Fund and the Republic of Cyprus through the Research Innovation Foundation CELSIUS Project EXCELLENCE/1216/0039.

\section{AUTHOR CONTRIBUTIONS}

G.Z, P.H., and J.L. conceived and designed the project. G.Z. and J.L. led manuscript writing. G.Z., Y.P., A.N., M.A., E.B., F.D., K.E.D., L.K., T.O., G.S., R.Z performed simulations and/or analyzed the data. G.Z., P.H., Y.P., and J.L. interpreted results. All authors assisted in manuscript writing and preparation.

\section{COMPETING INTERESTS}

The authors declare no competing interests.

\section{ADDITIONAL INFORMATION}

Supplementary information The online version contains supplementary material available at https://doi.org/10.1038/s41612-021-00178-7.

Correspondence and requests for materials should be addressed to G.Z.
Reprints and permission information is available at http://www.nature.com/ reprints

Publisher's note Springer Nature remains neutral with regard to jurisdictional claims in published maps and institutional affiliations.

(i) Open Access This article is licensed under a Creative Common Attribution 4.0 International License, which permits use, sharing, adaptation, distribution and reproduction in any medium or format, as long as you give appropriate credit to the original author(s) and the source, provide a link to the Creative Commons license, and indicate if changes were made. The images or other third party material in this article are included in the article's Creative Commons license, unless indicated otherwise in a credit line to the material. If material is not included in the article's Creative Commons license and your intended use is not permitted by statutory regulation or exceeds the permitted use, you will need to obtain permission directly from the copyright holder. To view a copy of this license, visit http://creativecommons. org/licenses/by/4.0/.

(c) The Author(s) 2021 